\title{
Free Spirits
}

Idealism and Perfectionism

\section{Sophie Djigo}

\section{(2) OpenEdition \\ 1 Journals}

Electronic version

URL: http://journals.openedition.org/ejpap/911

DOI: 10.4000/ejpap.911

ISSN: 2036-4091

\section{Publisher}

Associazione Pragma

\section{Electronic reference}

Sophie Djigo, «Free Spirits », European Journal of Pragmatism and American Philosophy [Online], II-2 | 2010, Online since 21 December 2010, connection on 01 May 2019. URL : http://

journals.openedition.org/ejpap/911; DOI : 10.4000/ejpap.911

This text was automatically generated on 1 May 2019.

\section{(c) $(1) \odot$}

Author retains copyright and grants the European Journal of Pragmatism and American Philosophy right of first publication with the work simultaneously licensed under a Creative Commons AttributionNonCommercial-NoDerivatives 4.0 International License. 


\title{
Free Spirits
}

\author{
Idealism and Perfectionism
}

\section{Sophie Djigo}

\section{Introduction}

1 The current interest in moral perfectionism owes much to Stanley Cavell's works on the constitution of Emersonian perfectionism. If perfectionism can be considered as an ethical dimension already present in Plato's and Aristotle's philosophical quest for good life, it is important to underline the link between studies flourishing today on this issue and what one may call the "Emerson revival." I am struck by the similarities between this current revival and the "Emerson boom" that happened in the German-speaking world and the fin de siècle Austria, about a century ago. Comparing these two Emerson waves should lead us to a better understanding of the European affiliation with moral perfectionism, which is reflected in the importance Cavell attaches to Nietzsche.

2 In his introduction of This New Yet Unapproachable America, Cavell includes two texts, the first one from Nietzsche and the second from Emerson, and develops paths of philosophical "circulation." He continues with comments on an excerpt from the beginning of Genealogy of Morals, saying that he is first and foremost interested in the kind of reorientation that Nietzsche inflicts on moral philosophy. That is: Nietzsche does not so much wonder who we are (since we are strangers to ourselves), as where we may find ourselves - if at all. "What chance" Nietzsche asks, "do we have of finding ourselves one day?" For Cavell, this question appears like an echo of Emerson's essay "Experience," which starts precisely with the question: "Where do we find ourselves?"1

3 The similarity between Emerson and the greatest European immoralist shows the ethical influence of Emerson's works, especially as a moral experimenter, "an endless seeker" as he depicts himself in "Circles." That ethics supposes a quest, and not a set of given principles or values; that it implies that one ought to look for one's own path, for a personal way of living and for a way of inheriting a common culture; that we are unceasingly trying to reach a better self, a possible self - all these elements are shared by 
Emerson as well as his German reader Nietzsche and also his Austrian admirer, Robert Musil. By looking more closely at the influence the American minister had on Nietzsche and Musil, as well as at their ways of re-appropriating Emerson's legacy, we can come to outline the idea of a certain version of moral perfectionism, which would be a kind of ethics peculiar to free spirits.

My goal for this paper is twofold. First, I want to point out congruencies between these three thinkers, (congruencies that are ultimately based on Emerson's influence on both European thinkers) and to give an account of moral perfectionism on the basis of the figure of "the free spirit" (freier Geist), which appears to play a crucial role in the ethical reflections of all three of them. Secondly, I will focus on the tension between idealism and pragmatism and the way in which it is affecting the ethics of the free spirit. Roughly speaking, the free spirit is characterized by his or her ability to think for him - or herself - an autonomy which also constitutes a moral deed. There is thus an ethical demand for thoughts we are personally convinced of, rather than for thinking something because everybody does so. Considering that expressing one's conviction is in itself an ethical demand, and in this regard perfectionism tends toward pragmatism. However, a further question arises: if the personal quest for a better self is at the heart of moral perfectionism, are we not in need of an ideal of what this better self should look like? In other words, does moral perfectionism imply at least the temptation of idealism (if not idealism at all)? And is there not a contradiction between the practical nature of selfaffirmation and the attainment of moral ideals?

This question is all the more worth posing since, as we know, Emerson is usually presented as a leading figure in the transcendentalist movement, which is a version of idealism. Nietzsche's view of moral values has likewise been defined as "philological idealism," and Musil's reflections on ethics are torn between a sharp criticism of idealism and the constant insistence on the need for ideals in moral life. I will argue that, if the free spirit is to be considered as a figure of moral perfectionism, we should neither take it to be an idealist nor an anti-idealist pragmatist notion. In order to grasp the originality and the point of moral perfectionism as a pursuit of a better future self, it is necessary to analyze the complex role ideals play in moral practices. And I think it is very important to differentiate anti-idealism and a complete rejection of moral ideals. I will argue that the free spirit, while anti-idealist, remains attached to ideals that can guide one's attempt to personal improvement.

\section{The Free Spirit and Moral Perfectionism}

My point in this first section is not to give any definition of what moral perfectionism is or should be, as I am convinced that any such attempt would be reductive regarding this ethical dimension of our lives. I would rather propose an image of what it means to be perfectionist in the sense of the free spirit. This figure embodies the exploration of creativity in morality, and its freedom is not a natural or anthropological property, but the result of a process of liberation. Thus, the freedom of the free spirit is never acquired, it always remains to be achieved to such an extent that action is interwoven in a dynamic ethics. Here, a parallel can be made between this idea of a freedom we are always looking for and the Emersonian "unattained but attainable self." We know this famous expression, according to a moral action must be seen as a renunciation of who we already are. To be an ethical agent requires that we give up our 
often comfortable and secure place, our ready-made or realized self, in the hope of another self, which is possible (attainable). There is a strong recommendation in these words of leaving reality to discover a possible self and a possible way of living, at the risk of loosing oneself. This preference for possibility is also at stake in a passage Cavell quotes from Nietzsche about a call for the unknown, for leaving our place in order to try to find ourselves. The free spirit has the strength to abandon his habits, his social and moral inherited values. It is not a matter of bringing a new foundation or of replacing an older order by a new one; the point is rather to abandon the very idea of grounds and to reappropriate one's culture in a critical and personal way. This is the very challenge of the free spirit: not to rebuild morality, but rather to learn to think on one's own.

It is this capacity that defines the free spirit in Nietzsche's Human, All Too Human, when he says :

We call 'free spirit' the one who thinks in a different way from what he is expected to do regarding his origin, his milieu, his condition and his position, or regarding the prevailing opinions of his time. ${ }^{3}$

The autonomy of one's thought presupposes the difference between the real and the possible, hence the capacity to be able to see what is possible beyond what is real, beyond social conventions and external determinations. The thing is that, according to Nietzsche, most of us are used to thinking in a realistic way, whereby "realistic" means a poor dependence on the already-made. To be realistic, in this sense, means to be conservative and to avoid doing something different if it runs the risk of not fitting into our real world, or of remaining too far removed from ordinary life. This kind of inertia is the opposite of the feeling of self-dissatisfaction that drives the free spirit. The free spirit is motivated by the conviction that a better world and a better self are possible. Thus, the free spirit is accurately defined by Musil as the man of possibility.

Indeed, Musil's anthropological typology is rooted in the Enlightenment's traditional interest in possibility and utopia. I shall discuss the link between idealism and this sense of possibility in the next sections. What I want to point out now is the distinction Musil makes in his novel between two types of men: the man of reality and the man of possibility. Regarding this second type, he writes in The Man without Qualities:

The man who is endowed with [the sense of possibility] won't say, for instance: here happened, will happen, must happen such and such things; but he'll imagine: here could, should happen such and such things; and when he's told that a thing is just like it is, he thinks that it could be just as well different. Then, we could simply define the sense of possibility as the faculty to think everything that could be "as well," and not to attach more importance to what is than to what is not. ${ }^{4}$

It is striking that Musil uses Emerson's characterization of the free spirit to describe this man of possibility (who is also the man without qualities after whom the novel is named). Plenty of commentators have underlined the proximity of Musil's man of possibility (named Ulrich in the novel) and Nietzche's freier Geist, without, however, taking the next step, which would lead to Emerson. The connection with Nietzsche appears explicitly in the novel, in a passage in which Ulrich is having a conversation on morality with his sister Agathe. This is an amazing moment when the couple reflects on Ulrich's suggestion of the "ethics of the next step." This conception takes ethics to be a dynamic process, stressing the morality of the agent rather than that of the action and taking account of his motives rather than the practical results of his actions. In this ethical perspective, rules are not the determinants of action, because they are too general to be operative in every particular case. There is no social or stable criterion for acting, so that Ulrich is 
advocating for "moral robbers," who are defying social morality in order to defend their sense of truthfulness and their convictions. Suppressing the double constraint of coherence and social conformity, what matters is the next step; not what has been done or real past deeds are decisive, but a possible future action is the real concern.

It is in this context that Ulrich refers to Nietzsche's freier Geist. ${ }^{5}$ From what has just been said, one could think that Nietzsche's immoralism should be invoked in order to sustain the ethics of the next step as a morality without external groundings. In a startling reversal, this invocation is introduced as an answer and, moreover, as a way of limiting Agathe's boldness when she discusses the ethics of the next step. Taking her brother at his words, and testing his sympathy for "moral robbers" and Dostoievskyan criminals, she asks "What if it was me committing a murder?" In asking this question, she points out the idealistic tendency of her brother's notion of ethical possibility in a very subtle way. Thus, she brings their moral concerns back to reality in a very pragmatic way: What if she were killing her husband?

In this attempt to test the practicability of immoralism, Agathe compels her brother to reconsider his own discourse on ethics. Here, the reference to Nietzsche will help him to defend a more pragmatic vision of the free spirit: "Nietzsche himself," Ulrich says, "enjoins free spirits to observe certain outward rules for the sake of their inner freedom."

${ }^{6}$ In this scene, Nietzsche becomes the guarantor of moral order! The difficulty is to reach such a compromise between outward social morality and inner personal creative ethics, or, in other words, to imagine new possibilities of acting in the limits of social agreement. It is another way of expressing the tension I have already evoked between the ideal and the real, since the sense of possibility appears as an idealistic movement of thought whereas social rules embody the reality of our social practices.

In another conversation between brother and sister, which is described a few pages before this scene, Ulrich had already quoted Emerson, without mentioning his name, in order to show the difficulty of immoralism and his demand that immoralism should be another morality, a stronger one and not relativism. The quotation is in fact from "Circles," where Emerson writes:

"The virtues of society are vices of the saint."

15 This statement distinguishes between social values and a higher morality which is an ideal horizon at this point of the reflection. When Agathe speaks of killing her husband, she tries to rely on Emerson's quotation, and her justification consists in considering her murder as an antisocial action, not an immoral one. In order to ward off Agathe's appeal to murder, Ulrich feels the need to defends himself by distancing himself from Emerson:

"I didn't say that the vices of society were virtues of the saint!"

This reversal proves his sensibility to moral limits and the refusal to (mis-)understand immoralism as a complete reversal of traditional values. Being a free spirit does not mean that one should think murder is good. A mere reversal would be far too easy and lead to absurdities. True immoralism does not consist in rejecting all actual values, but in being able to re-appropriate these values through a critical reflection and to envision a higher morality, free from compromises. In this sense, the free spirit is also able to account for the personal conflict between, on the one hand, his inner conviction and its demand for truthfulness and, on the other, conformity and its propensity to obey moral and social rules. 
To go deeper into the filiation between Musil, Nietzsche and Emerson, we must also relate Nietzsche's notion of the freier Geist to Emerson, who is the first to employ the notion of the free spirit. Indeed, I am convinced that Nietzsche's idea of freier Geist was modeled on and is a refinement of Emerson's original conception of the "free spirit," which, Emerson tells us, "sympathizes not only with the actual form, but with the power or possible forms."

This is, I think, the very key to our understanding of the link between ethics and the sense of possibility in Nietzsche and Musil, who appear to have taken this sentence seriously and to have developed it in personal and remarkable ways. Other passages support this idea of the existence of two types of men, one of which is feeble-minded, corresponding to Nietzsche's slave and Musil's man of reality, while the other is gifted with moral strength and power, like Nietzsche's master or Musil's man of possibility. Thus, Emerson writes also in his essay Power: "The feeble man can see the farms that are fenced and tilled, the houses that are built. The strong man sees the possible houses and farms." ${ }^{\prime \prime}$

This again suggests that Emerson's influence on Nietzsche and Musil's conception of immoralism as an ethical implementation of the powerful sense of possibility is not to be underrated. Immoralism is neither conceived as moral relativism nor as cruelty or a total absence of morality. Instead, it is "proving us," as Musil has it, "that life works also differently." It is in this denial of an absolute approach to any existing morality that the sense of possibility constitutes an ethical power. It is the power to change the real in order to reach the "unattained, but attainable self."

\section{Emerson: "The Ideal is the Real"}

20 According to Emerson, the capacity to think on one's own corresponds to what he calls "self-reliance," the power to rely on what one is and thinks. Thus, Emerson exhorts us in his essay entitled Self-Reliance:

"Trust thyself! Every heart vibrates to that iron string."10

21 To trust oneself requires that one frees oneself from social conformity and that one is capable of relying on one's imagination of possible ways of living. This exhortation is made possible by the discovery of the very nature of reality. Reality is not a constraining prison, as Emerson seems to depict it in his essay Fate. If we are helpless in the face of natural forces that constitute our destiny, we can recover power and freedom only by adopting another conception of the real. Indeed, Emerson already wrote in his early lectures: "The Ideal is the Real. The Actual is but the apparent and the Temporary." 11

This identity between the ideal and the real is surprising in many ways. First, it seems to obscure the deep hiatus between ideality and reality in so far as the proper definition of ideality supposes that it is not sensible, that it does not belong to our perceptual world. Shall we read this identification as a sign of Emerson's idealism, a landmark concept expressing his wish to order and conceive reality according to ideals? One has to acknowledge that Emerson's resort to the ideal is very subtle and has to be distinguished from philosophical idealism such as Kant's or Hegel's. If we link this quotation to several essays written in the 1840s, for instance Experience or Nominalist and Realist, we can take Emerson to be saying that the real is never given, that it is always to be looked for, but not only as part of a quest for truth about the world. His point is rather to arouse our 
attention to the fact that the real, since it is never given, might be shaped by us - shaped by our ideals.

Far from defending a kind of Platonic metaphysical realism, then, Emerson is tackling the idea that immediate experience is more important than possible experience. We seem to prefer an ontology of the actual to one of the possible. Emerson shows that the important difference to be made is not between the real and the possible, but rather between the actual reality and the possible one. From this point of view, the role of the ideal is neither to move us away from reality nor to cast reality in an idealistic mold, but to revive the power of our imagination by proposing ideas of a possible world (and of a possible self). Thus, the point is not to choose between an ideal world and a real one, but to find how to realize ideals in our practical life.

Indeed, the representation of an ideal world different from the one we inhabit is explicitly rejected by Emerson in his late works. In his journals, for example, he evokes one of his conversation with his friend Sampson Reed:

In town I also talked with Sampson Reed, of Swedenborg and the rest. "It is not so in your experience, but it is so in the other world." "Other world?" I reply, "there is no other world; here or nowhere is the whole fact [...]"12

This refusal to confine ideals in a second other world indicates an evolution in Emerson's thought from transcendentalism to pragmatism. If it makes sense to hold on to ideals within a pragmatic context, it is only to the extent that they have an effect on our world. The purpose seems in fact to transform reality through ideals; Emerson speaks in this regard of "the transformation of genius into a practical power." ${ }^{13}$ Likewise, the "true romance which the world exists to realize" refers to the imagination of possibility, in the Emersonian version of idealism. This transformation is not obvious. Indeed, not all our ideals can be carried out, and too often, theoretical boldness leads to ideals which are deprived of the slightest practical value. The idealist must also be a realist, otherwise ideals will remain empty dreams.

This transformation requires experimentation and expression. Experimentation is needed to explore the imaginative area of possibilities. The renunciation of secure certitudes is not necessarily painful, since it also constitutes a liberation and opens onto new possibilities. In Circles Emerson depicts himself as an experimenter, saying:

I unsettle all things. No facts are to me sacred; none are profane; I simply experiment, an endless seeker, with no Past at my back. ${ }^{14}$

Ethics appears in this quotation as an endless quest, bringing morals into play unceasingly, confronting ideals with particular contexts. Like the real, ethics is never given, never acquired, always to seek and to find through attention and imagination. In this sense, ethics is itself an experimentation without the purpose of reaching absolute principles. The fact that no virtue should be taken as definitive is not something negative, since it makes it possible to imagine different possibilities without being censored by sacred moral values.

This idea is also related to one of the elements which constitutes Emerson's skepticism : the uncertainty of our perception of reality, and therefore, our lack of knowledge of reality. This issue has been brilliantly developed by David Robinson. Commenting on Emerson's Experience, he argues:

The problem of not knowing, stated earlier as threatened perception, has become the solution of not knowing, stated now as 'inscrutinable possibility. ${ }^{15}$ 
This indicates that our relationship to the world is problematic in two ways: first, because our attachment to reality through habits prevents us from imagining how to change and to improve reality; second, because our lack of knowledge of reality is also an obstacle to our capacity of acting in a blurred and uncertain world. The limits of our knowledge, instead of sustaining skepticism, is also a means to overcome our deficient link to reality by the sense of possibility, even if skepticism persists through this sense insofar as it tackles ideals and their articulation to our practices.

To go further, we can assert that the difficulty of this sense of possibility relies on the fact that the imagination of new possibilities of living can only develop from real experiences, because of the risk of abandoning the real ground. It is not easy to get free from social conventions and actual habits, and at the same time to keep a sense of what is realizable. The aim of the Emersonian free spirit must not be confounded with "manipular attempts to realize the world of thought"16 which would be an expression of idealism proper. Instead of elaborating a theoretical yet unattainable world (idealism), the free spirit uses his culture and his past as a springboard to imagine possibilities which will not be disconnected from reality.

Emerson's criticism of idealism can also be grasped in his descriptions of contemporary utopian experimentations such as Fruitlands or Brook Farm. When he comments on his friends' Lane and Alcott plan to establish a communitarian farm, Emerson elaborates on the very problem of idealism. Indeed, idealism is initially presented as a hypocritical attitude replacing action and the courage to act by beautiful speeches and theories. But this is not exactly the problem. Let us remember what Emerson says when he confesses his own withdrawal in Fruitlands project: "I am always insincere, as always knowing there are other moods." 17

Emerson's insincerity must not be seen as a betrayal of his ideals, but rather as the expression of his skepticism towards ideals which seem far too theoretical and disconnected from reality. Mistrusting theory also as a flipside, namely that one puts one's trust in the evanescent experience. Attention to experience and its changes results in a change in mood, say when enthusiasm is replaced by skepticism. Theories are often too general and unable to fit into the particularity of changing experience. Because Lane's and Alcott's utopia appears as too theoretical, it is doomed to fail. It was already the case with Brook Farm. In Experience, Emerson goes back over this failed reformation attempt and indicates to what extent skeptical doubt is necessary for the pursuit of ideals, insofar as it reminds the demand for practicability:

If a man should consider the nicety of the passage of a piece of bread down his throat, he would starve. At Education-Farm, the noblest theory of life sat on the noblest figures of young men and maidens, quite powerless and melancholy. It would not rake or pitch a ton of hay; it would not rub down a horse; and the men and maidens it left pale and hungry. ${ }^{18}$

Emerson's insincerity thus sheds a light on the initial identity between the ideal and the real. This identification must be understood through the skeptical imperative that ideals should be attached to practical values and can be realized in our world. Insincerity is not a renunciation to ideals, but a refusal of pure theories unable to deal with our world. In this perspective, the ideal and the real are strongly interlinked, since the first is necessary to change the second, and the second is the only world we live in, which includes limits that the sense of possibility must take into account.

European Journal of Pragmatism and American Philosophy, II-2 | 2010 


\section{Nietzsche, Self-Knowledge and Idealism}

While thinking of self-improvement as a central element of moral perfectionism, one could evoke Nietzsche's superman (Übermensch) which seems to provide such an image of a better self. Consider on the one hand, the implication of the concept of melioration in the "superman," and on the other hand, Cavell's references to Nietzsche as a figure of moral perfectionism that gives rise to controversy about the potentially elitist nature of perfectionism. I shall consider whether Nietzsche's free spirit corresponds to the elitist image of the superman. I would argue that the free spirit is another, more accessible figure than the mysterious superman and that it would be misleading to confound these two different images. To spur the traces of Nietzsche's reading of Emerson, is particularly fruitful in order to grasp the place of the free spirit in his philosophy. It also helps explain his continuous challenge to articulate ideals and practices and his rejection of the dualist opposition (distinction) between theory and practice.

The free spirit appears most explicitly in Human, All Too Human, a book dedicated to "free spirits. ${ }^{19}$ Commenting on this work in Ecce Homo, he writes :

Human, All Too Human is the monument reminding a crisis. It is entitled a book for free spirits: almost each of its sentences expresses a victory - by it, I've freed myself from what is not involved in my nature. Is not involved, for instance, idealism. ${ }^{20}$

This remark calls attention to the fact that, in order to understand what a free spirit is, one should connect it with the criticism of idealism rather than with the idea of excellence and the promotion of virtues which are at stake in the superman's figure. Furthermore, Cavell's quotation in its turn refers to this issue of idealism, insofar as it begins like that: "We are strangers to ourselves." Indeed, this estrangement reveals the contradiction between the need for knowledge, which is also typical of the philosopher, and a lack of self-knowledge. How can we claim truth and knowledge whereas we do not even possess this primary knowledge of ourselves? This paradox is one possible way of making the free spirit emerge, since he appears as the bearer of the quest for selfknowledge.

Self-knowledge is the purpose of the free spirit, which is to say that he is not as concerned with truth as with probity and truthfulness. He is interested in being aware of his own ideas, conceptions, preferences, and his problem is to develop them without being influenced by prevailing opinions and social norms. Nietzsche's analysis of the philosophical knowledge impulse shows that philosophers aim at gathering the variety of experiences, in all their multiplicity and evanescence, in an ideal unity. And they are doing this by building systems which sort out elements of reality, abandoning those elements which resist being integrated in the system. In other words, the philosophical task consists in reducing the unknown to the already-known. This is the proper task of idealism: it reduces reality to an ideal order, a product of thought.

Thus, idealism is an attempt to flee from reality, to ignore the unknown and to reject what Nietzsche also calls the tragic dimension of life: the conflict between contradictory impulses which resist unification. Unlike the idealist philosopher, the free spirit is the one who is able to recognize both this conflict and its passionate nature. Moreover, he is looking for the unknown, accepting the multiplicity of experience beyond the frame of our concepts and the possibility of different conceptual perspectives. This openmindedness leads him to surpass himself; a movement which characterizes perfectionism 
and presupposes the experience of loosing the realized self in order to look for the possible, still unknown self. On this point, Nietzsche is very close to Emersonian perfectionism, a moral quest based on the discovery of unimagined aspects of one's personality.

Thus, the free spirit is defined as a realist. Instead of looking for an ideal perfection, or the achievement of his best qualities and virtues, he is focusing on the reality of his own tendencies and plurality of affects. By doing this, he stops avoiding life. The emphasis on life prevents us from an idealistic understanding of perfectionism here: if there is a demand for self improvement, it does not consist in the elaboration on an ideal of perfection and the subsequent attempt to reach it. On the contrary, the fundamental issue concerns the gap between thought and life, between the ideal and the real, and the aim of the free spirit is to bridge it. Now, according to Nietzsche, life is engaging our body and a range of passions and interlinked and conflicting affects.

Idealism is precisely the tendency to forget this bodily dimension of ours while it is in fact the very origin of our ideals and of our ways of thinking. In the genealogical perspective, ideals are "the distorted expressions of our body's desire," ${ }^{21}$ a form of our affective impulses which aims at the same time at making this bodily origin disappear. To the extent that these impulses are anchored in personal preferences and subjectivity, one can understand why Nietzsche also considers ideals as values: they constitute various evaluations, and evaluation is in itself a way of affirming one's preference, the expression of one's prevailing relationship of one's body with life. The link between ideals and practices is reinforced in this conception of ideals as expressive of evaluations originated in our corporal dimension. As Nietzsche writes:

Then comes the upper stage: the attempt to create an ideal (ein Ideal dichten). This precedes even the upper stage: precisely to live this ideal..$^{22}$

The tragic aspect of our condition not only consists in the tension between different impulses at the basis of our thinking about the world, but also in the tension between thought (ideal) and life. At his point, the criticism against idealism opens up onto a strong double demand: first, the demand that life should be thought, grasped by our concepts and our language; second, the demand that ideals should be lived in practice. In my view, Nietzsche is not totally rejecting idealism (or philosophy); he is rather advocating a reciprocal conversion of thought and body (actions and affects). In this view, we can remember Nietzsche's definition of ideals as "the coded language of affects" (Zeichnensprache der Affekte). ${ }^{23}$

41 If we sum up Nietzsche's criticism against idealism, we can see that it is, on the one hand, very forcefully acting against metaphysics and systematization in philosophy, but also, on the other hand, involved in the movement of perfectionism as a quest related to selfknowledge. Indeed, by underlining the affective origin of ideals and of everyone's perspective, Nietzsche is also propagating a form of soul-searching. His own point of view is anchored in a personal impulse. The power of his analysis is this deep lucidity, the acceptance of the link between his own way of thinking and his affects, from which results a deep self-reliance, the capacity to trust one's body, preferences, and experiences, while acknowledging that these elements are not absolute and universal producers of truth.

42 In face of this modesty and self-awareness of Nietzsche, Heinz Wismann suggested to refer to his notion of idealism as a "philological idealism" in order to account for both Nietzsche's sharp criticism of idealism and his recognition of the status of his own 
assertions: these are also rooted in an idiosyncratic life of affects, biased by this instinctive ground, irremediably subjective. That is why the issue of idealism leads him to re-evaluate the priority given to "truth" in regards of truthfulness. The need for truth corresponds to a certain impulse and a particular (reductionist) relation to reality, whereas truthfulness indicates the relation to one's own preferences and probity, which do not require us to reject ideals, but instead to live them, to realize them in our life. The issues of truth and objectivity do not disappear, but they are not the topics Nietzsche is most interested in. He is concerned instead with our way of being truthful to our affective motives, like the free spirit who has been able to free himself from his own impulses by accepting them and the tendency to ignore them.

This perceptiveness is the ground of the next step to experiment, The example of free spirits offered by Nietzsche is Christopher Columbus, the great symbol of the quest for the unknown. The experiment (Versuch) characterizes the way of living like a free spirit. The genealogical approach continues its work of mining culture and prejudices, and allows the free spirit to explore step by step the unknown without preconceived ideas, being open to adventure and new discoveries. The experimental method is also a return to reality, to the solid world of our Erlebnisse. The scientific metaphor is not innocent: it expresses Nietzsche's attachment and admiration for science as model of intellectual probity and truthfulness.

Nietzsche's philosophy of exploration and his criticism of idealism are two sides of the same conception of ethics, understood as intellectual integrity and a search for ourselves. The purpose is still the attainment of knowledge, but in the specific form of selfknowledge that requires us to overcome the dualism opposing ideal and life. Selfknowledge implies the exploration of oneself, including one's body, and to acknowledge one's preferences and concerns. It involves a certain way of thinking by elaborating ideals conceived as being anchored in passions, and a certain way of living by trying to realize these ideals or to imagine other ones. In this view, exploring reality overlaps with imagining possibility. Free spirits find their own paths by relying on their past experiences as well as by being open to the adventure into the unknown.

\section{Musil, "An Idealist Without Idealism"}

Robert Musil, who had no shame in confessing that he had strongly been influenced by both Emerson and Nietzsche, developed a version of the free spirit which tries to overcome the hiatus between the ideal and the real. My argument is that in the third section of the novel, Musil's main character Ulrich represents the free spirit and that his story offers an image of moral perfectionism. In The Man without Qualities, the mathematician Ulrich is confronted with a painful experience: the failure of the successive utopia he has imagined. So, at the end of the second section of the novel, he is increasingly concerned with the urgency to bridge the gap between ideals and reality, the failure of which continues to threaten the possibility of action and of improvement. The plot can be summarized as follows: Ulrich wishes that human beings would act more fairly and to the purpose of a better life. But this desire comes up against the unrealizable nature of many ideals of a good life, or, on the contrary, against a lack of ideals in our practical lives From then on, the aim of the moralist Ulrich is to find ideals which are compatible with reality. This is the role of the sense of possibility. 
Trying to satisfy this requisite, Ulrich does not suggest an ideal system which would be better than the others. His change is not of a theoretical nature, but of a practical one: he adopts another attitude. This attitude consists in being open to the unexpected, to the unknown, and in acting step by step. The meeting with his sister brings an end to the theoretical moment of his life. He concludes that if he wants a fairer life, he has to find one himself: to find a personal way of being which is based on conviction. Here again, we can read Musil's interest in conviction as being closely related to his reading of Emerson's self-reliance. The ideal we are thus offered is to do only what we are convinced of, to stop doing anything which would be insignificant for us. In other words, Musil's motto could be "Never act without conviction."

The notion of conviction not only concerns our actions, but also our relation to ourselves. To act convincingly presupposes that we know ourselves well enough to be sure of the motives and meanings of our actions. Furthermore, this self-knowledge includes dissatisfaction with these motives and meanings: it is because I am not satisfied with what I did, wished or said, that I am trying to be different and to change myself by exploring ways of being myself which could be more compatible with my own changing idea of this "better self."

From this point of view we can examine Musil's rejection of idealism as the other side of his development of moral perfectionism. Indeed, Musil criticizes idealism insofar as idealism constitutes a metaphysical flight from reality. Idealism suggests ideals that are always unattainable and to which we can only aspire. Instead of living our ideals, we live for ideals which remain confined in the world of our thought. Musil employs the term "pragmatism" to refer to the cynical activism which is only concerned with the results, the performance of action, rather than its motives, its value. It is a kind of rough consequentialism.

49 A more positive notion of pragmatism emerges in the novel when Ulrich appears as a perfectionist concerned with the question how to live. The rejection of idealism opens up the ideal of motivation or conviction. This ideal is not unrealizable and it is rooted in the subjective and affective dimension of individual morality. Self-improvement is depicted as a search for what is important and makes sense. Self-transformation thus implies an exploration of this personal universe of motives and of our capacity to make sense of anything. That is why we can gain motivation only step by step, according to our capacity to be aware of reality, to make sense of our experience, to imagine possible motives and meanings. In the novel, this attempt to act with conviction is realized step by step through Ulrich's conversations with Agathe, through their mutual trust, friendship and love. This itinerary to find who one can be includes a part of experiments and failures, which are inseparable from our practices. It must be pursued in the constant renewing of conviction. In Ulrich's words: "Faith must not be an hour old!"24

Ideals, then, are nothing less than the representations of the self we could and would like to be. They are necessary for self-transformation since they constitute the temporary step to reach. If one needs self-knowledge in order to make clear who one wants to be or where to be in regard of the previous generation and of one's culture, self-transformation is also sustaining this knowledge. Abandoning ideals would mean abandoning selfimprovement and remaining the same, keeping one's realized self. It is because he cannot bear this idea of moral stagnation and conservatism that Musil calls for selftransformation through conviction and re-appropriates the romantic and Nietzschean motto: "Become who you are!" His character in the novel is finally depicted as "an idealist 
without idealism," ${ }^{25}$ a device which expresses that the reject of metaphysical idealism is accompanied by the attachment to ideals as representations of a possible better self.

\section{Conclusion}

51 The underestimated filiation between Emerson, Nietzsche, and Musil is peculiarly fruitful when it comes to the issue of moral perfectionism and its place in the debate opposing idealism and pragmatism in the 21th century. As the image of a peculiar type of man, the free spirit constitutes a way of depicting what moral perfectionism could look like and how it is related to ideals. The common ground of these three versions of the free spirit consists essentially in the notion of possibility. Possibility, usually seen as a logical concept in philosophy, is given an ethical importance. As such, it indicates a certain moral strength - call it self-reliance, probity, or conviction - which allows the individual to explore even the most obscure parts him or her-self, to be critical of oneself, and to accept the adventure of leaving this unsatisfied self and to search for a possible better one.

In this view, the sense of possibility is rather an ethical faculty than a purely intellectual power, since it involves self-criticism, accuracy, and imagination. But it makes sense only if it has practical effect, especially the effect of leading one to become who one is. Yet the ability to think on one's own, while already conceived by our three thinkers as a moral act, is not in itself sufficient; their very purpose is not only the autonomy of one's thought, but the power to act according to one's own thought. This point allows us to argue that moral perfectionism is pragmatic insofar as it demands practical effects and actions. But this pragmatist orientation, because it is threatened by cynical activism or conformity, must be guided by personal ideals conveying the image of a better "unattained, but attainable" self.

\section{NOTES}

1. Emerson R.W., (1984), Experience, in J. Porte (ed.), Essays \& Lectures, New York, Cambridge, Press Syndicate of the University of Cambridge, 471.

2. Cf. Wismann H. \& Bollack M. (eds.), (1983), Philologie et herméneutique au XIXe siècle 2, Göttingen, Vandenhoeck und Ruprecht.

3. Nietzsche F., (2000), Human, All Too Human, I, §255, trans. by G. Handwerk, Stanford, Stanford University Press, 155.

4. Musil R., (1978), Der Mann ohne Eigenschaften,I, 4, in Gesammelte Werke, I, 9 Bänden, hrsg von Adolf Frisé, Reinbek bei Hamburg, Rowohlt Verlag, I, 4. My translation. I will refer to this novel by the abbreviation MoE.

5. In a brilliant paper, David Midgley is commenting on this passage and the connection between Musil and Nietzcshe on morality. Cf. Midgley D., (2003), Experiments of a Free Spirit: Musil's Explorations of Creative Morality in Der Mann ohne Eigenschaften, in R. Görner \& D. Large (eds.), Ecce Opus: Nietzsche-Revisionen im 20. Jahrhundert, Göttingen, Vandenhoeck \& Ruprecht, 111-24. 
6. MoE, II, 15.

7. Emerson R. W., Circles, in Essays and Lectures, cit., 411; MoE, II, 10.

8. Emerson R.W., Power, in Essays and Lectures, cit., 974.

9. MoE, II, 30.

10. Emerson R.W., Self-reliance, in Essays and Lectures, cit., 260.

11. The Early Lectures of Ralph Waldo Emerson, ed. by R. E. Spiller, S. E. Whocher, and W. E. Williams, Cambridge, Harvard University Press, 1959, vol. 2, 227.

12. The Journal and Miscellaneous Notebooks of Ralph Waldo Emerson, ed. by W.H. Gilman et al., Cambridge, Belknap Press of Harvard University Press, 1960-82, vol.8, 182-3.

13. Emerson R. W., Experience, in Essays and Lectures, cit., 492.

14. Emerson R. W., Circles, in Essays and Lectures, cit., 412.

15. Robinson D. M., (1993), Emerson and the Conduct of Life. Pragmatism and Ethical Purpose in the Later Work, Cambridge, Cambridge University Press, 61.

16. Emerson R. W., Experience, in Essays and Lectures, cit., 492.

17. Emerson R. W., Nominalist and Realist, in Essays and Lectures, cit., 587.

18. Ibid., 478.

19. We can read on this point the remarkable study by Wotling P., (2008), La philosophie de l'esprit libre, Introduction à Nietzsche, Paris, Champs Flammarion.

20. Nietzsche F., (2004), Ecce Homo, III, §1, trans. by A. M. Ludovici, Edinburgh and London, Courier Dover Publications, 82-3.

21. Blondel E., (1986), Nietzsche, le corps et la culture. La philosophie comme généalogie philologique, Paris, PUF, 85.

22. Nietzsche F., Posthumous Fragments, spring-autumn 1881, 11, [258], digital critical edition: [ nietzschesource.org/texts/eKGWB].

23. Nietzsche F., (2008), Beyond Good and Evil, §187, trans. by H. Zimmern, Radford, Wilder Publications, 60.

24. MoE, II, 12.

25. Musil R., (2009), Nachlass, NM VII/15/19 : “Ein Idealist ohne Idealismus," Klagenfurter Ausgabe, Kommentierte digitale Edition sämtlicher Werke, Briefe und nachgelassener Schriften. Mit Transkriptionen und Faksimiles aller Handschriften. Hrsg von W. Fanta, K. Amann und K. Corino, Klagenfurt, Robert Musil-Institut der Universität Klagenfurt, DVD-Version.

\section{ABSTRACTS}

My goal for this paper is twofold. First, I want to point out congruencies between these three thinkers: Emerson, Nietzsche and Musil. Such congruencies are ultimately based on Emerson's influence on both European thinkers and lead to an account of moral perfectionism based on the figure of "the free spirit" (freier Geist), which appears to play a crucial role in the ethical reflections of all three of them. Secondly, I will focus on the tension between idealism and pragmatism and the way in which it is affecting the ethics of the free spirit. 